\title{
Cloud Computing Adoption: A Cross-Continent Overview of Challenges
}

\author{
${ }^{1}$ A. A. Dahiru and ${ }^{* 2}$ H. Abubakar \\ 1Department of Computer Science, Modibbo Adama University of Technology Yola, Nigeria \\ 2Department of Mathematics, Usman Danfodiyo University Sokoto, Nigeria
} [Corresponding Author: E-mail: hassan.abubakar@udusok.edu.ng]

\section{ABSTRACT}

Cloud computing continues to dominate information and communication technology (ICT) strategies globally through the provision of remote access to computing resources via the internet. With its inherent pay-per usage model, flexibility, scalability and other features, cloud computing is also set to transform economic activities around the world. This paper analyses and compares the challenges facing the adoption of cloud computing from a geo-regional context; Europe and sub-Saharan Africa. An institutional theory perspective is used as framework for analysis. Findings from Norway in Europe and Nigeria in sub-Saharan Africa show that there are several challenges to cloud computing adoption in both places that are similar but impact on adoption decisions in different ways. For instance, the key adoption issues used as bases for comparison in Norway viz. security, privacy and trust, cost, Service Level Agreements (SLAs), government policies and regulations, and loss of control over data can all inhibit or pose as hindrances to cloud computing adoption. Contrarily, in Nigeria, these issues are not seen as inhibiting cloud computing adoption. Furthermore, the findings show the profound effect of normative and coercive pressures in Norway that can impact negatively on adoption decisions and the absence of such pressures in Nigeria which seem to have a positive influence on adoption at present. Keywords: Cloud Computing; Adoption; Europe; Sub-saharan Africa; Institutional Theory

\section{INTRODUCTION}

Cloud computing is the delivery of computing resources via the internet as a service. The payper usage model, flexibility, scalability and other features of cloud computing has the potential to impact on different aspects of economic and social activities globally. Cloud computing is already playing an important role in information Technology (IT), commerce, finance, education, health and several other sectors. According to Greengard (2010), cloud computing changes the stakes for entrepreneurs, small and large businesses, and researchers. Much of the information systems literature on cloud computing however has largely been focused on the developed countries such as members of the Organization for Economic Cooperation and Development (OECD). This is not unconnected with the fact that majority of cloud services market is in Europe (El-Gazzar 2014). Even so, existing research has focused on cloud computing architecture, potential applications, and costs and benefit, while that of adoption has received little attention (Saya, Pee, et al. 2010). Kshetri (2011) is of the view that studies and surveys on cloud computing across other developing economies have been generally inconsistent. This research contributes to filling the literature gap in cloud computing adoption research with further emphasis on sub-Saharan Africa, a region where mainstream information systems (IS) research is lacking (Datta et al. 2005) especially by indigenous researchers (Walsham and Sahay 2006).

In this paper, analysis and comparison of the challenges facing the adoption of cloud computing from two regions; Europe and sub-Saharan Africa is conducted. An institutional theory perspective is used to organize the findings from Norway in Europe, classified as a developed country where the cloud market is considered to be matured (ElGazzar 2014), and Nigeria in sub-Saharan Africa, classified as a developing country and an early adopter (Dahiru, et al. 2014a) as well as the largest economy in Africa (National Bureau of Statistics 2014). To establish a basis for comparison and add rigor to this research, two research studies that both employed elements of the institutional theory for analysis are used. The first is the work carried out by El-Gazzar (2014) that examines the cloud computing adoption 
challenges in Europe from a Norwegian context and how to address these challenges. The second is that of Dahiru et.al (2014) which examines the adoption of cloud computing in sub-Saharan Africa with focus on Nigeria.

This research contributes to filling the literature gap in cloud computing adoption with the aid of institutional analysis. Findings from this research show that, the key adoption issues used as bases for comparison in Norway viz. security, privacy and trust, cost, SLAs, government policies and regulations, and loss of control over data can all inhibit or pose as hindrances to cloud computing adoption. Contrarily, in Nigeria, these issues are not seen as inhibiting cloud computing adoption; the reason being; the expectation of better and reliable services in the cloud compared to locally hosted services; and cheaper access to computing resources that enhances operations and service delivery which were hitherto difficult to access. The findings also show the profound effect of normative and coercive pressures in Norway that can impact negatively on adoption decisions and the absence of such pressures in Nigeria which seem to be enabling adoption at present.

\section{Related Work}

Cloud computing is the delivery of software and technology as services over the internet by service providers. According to the National Institute of Standards and Technology (NIST) (Hulme 2011), it is a model for enabling ubiquitous, convenient, on-demand network access to a shared pool of configurable computing resources (e.g., networks, servers, storage, applications, and services) that can be rapidly provisioned and released with minimal management effort or service provider interaction. In cloud computing, end-users do not require the knowledge of the physical locations or configurations of the systems that delivers relevant services to them. It also has other key features like elasticity of the amount of computing resources to be used to suit the "on demand" delivery of computing resources characteristics (Voorsluys, Broberg and Buyya 2011).

Countries in both Europe and sub-Saharan Africa are willing to explore such innovations like cloud computing that can promote efficiency, reduce cost and increase profitability. However, challenges that relates to adopting these new innovations can raise a lot of concerns and may vary from one location to another.

a. Cloud Computing Adoption Issues in Europe

As stated earlier, the cloud market is considered to be matured in the EU and decision makers are increasingly becoming interested in transitioning their applications to the cloud. Few studies have been conducted to examine actual challenges to cloud computing adoption in Europe. In the UK, for instance, the determinants of cloud computing adoption were investigated using the Technological, Organizational, and Environmental (TOE) framework by Lumsden \& Anabel (2013) and Alshamaila et al., (2013). The former study, which involved both small and large organizations, was able to confirm the high rate of cloud adoption in the UK. In the case of the latter, the study identified the main factors that play significant role in cloud computing adoption by Small and Medium Enterprises (SMEs) in the North East of England. Both studies identified issues such as compatibility, relative advantage, technology readiness, top management support and so on as the most important determinants of cloud adoption in UK organizations.

Werfs et al., (2013), have also investigated how a set of SME high-value software vendors are migrating their software products to the cloud using an adaptive socio-technical systems (ASTSs) concept. The study identified key emergent tensions in cloud adoption and proposed a way to manage those tensions, although the solutions may not necessarily be generalizable to all organizations as the study is still ongoing and relied heavily on limited data. Carcary et al., (2014), in an exploratory study, concentrated on developing a model for Irish enterprises transitioning to the cloud environment. The study did not find existing models to be suitable for adaptation but identifies one of the key tensions in adoption to be the degree of complexity and inherent characteristics of the enterprise. 
In Norway, El-Gazzar (2014) has made an effort to examine the state of cloud computing adoption and challenges by scoping existing literature and reports published by consulting companies, and official bodies, official online news articles, and documents published by official authorities.

b. Cloud Computing Adoption Issues in subSaharan Africa

Cloud services/applications used in many countries in sub-Saharan Africa currently include cloud hosted email services, SharePoint, Google applications and data storage services. A few companies are using cloud hosted SAP, enterprise resource planning (ERP) and microfinance banking operations and accounting packages.

Few studies have been carried out to explore the use of cloud computing in sub-Saharan Africa. The South African internet governance forum in its first issue paper introduced several emerging issues related to the use of cloud computing (Alex 2011). The issues introduced were related to internet broadband, economic development, and security privacy and trust issues. However, as clearly identified by Dahiru et al (2014a) in the paper, detailed analysis of the issues introduced was not carried out and thus could not provide or inform any sort of user or policy recommendations. In a recent study, Akande \& Van Belle (2014) proposed a framework that can be used to assess the readiness to adopt cloud computing by financial institutions in South Africa. The study, which also employed the TOE framework as a theoretical base found out that security and privacy, governance issues, inadequate cloud service level agreements (SLAs), vendor lock in, poor vendor transparency, inability to assess risks, confidentiality, integrity and availability are some of the barriers that impede the full implementation of cloud computing. An earlier work by Dahiru et al. (2014b) which this work partly builds upon, has established the ability of SaaS cloud applications use in sub-Saharan Africa to lower the cost of entry by reducing the initial capital required for start-up of new enterprises or the cost of system management for existing once as the case is in the global north. The study identified several cloud computing adoption issues faced by enterprises in
sub-Saharan Africa which includes: security, privacy and trust, fear of data loss, awareness, top management support, availability of good internet connection and cost. Some of the issues identified like security, privacy and trust and fear of data loss were found to have influenced adoption decisions positively for both existing and start-up enterprises.

In this research, elements of the institutional theory employed in the works of both El-Gazzar (2014) and Dahiru et.al (2014b) are used to analyze and compare the challenges associated with the adoption of cloud applications in Europe and sub-Saharan African. Institutions theory and its applications in the Information Systems (IS) field is discussed further in the next section.

\section{Institutional Theory}

The core concept of institutional theory is that organizational structures and processes tend to acquire meaning and achieve stability in their own right, rather than on the basis of their effectiveness and efficiency in achieving desired ends, such as the mission and goals of the organization (Miles 2012). According to Scott's (2008) conception of institutions, it comprises of "regulative, normative and cultural cognitive elements that, together with associated activities and resources, provide stability and meaning to social life" (pp. 48). In the view of DiMaggio \& Powell (1983), institutions exert three types of isomorphic pressures or effects, viz. coercive, normative and mimetic; and view the effects of cognition through mimetic isomorphism. The basic similarity in all institutional theoretical claims however, is that something identified at a higher level is used to explain processes and outcomes at a lower level of analysis (Clemens and Cook 1999). Jennings and Greenwood (2003) also suggest that the notion of institutional isomorphic pressures is akin to the concept of institutional pillars proposed by Scott (2008).

To expand on these pressures/pillars, coercive pressures originate from environmental sources such as those from a dominant customer or supplier, or from government regulations. Hence, these entities may have resources that make organizations dependent on them. Normative 
pressures result from the existence of relationships between members of a network which can lead to a consensus and the development of norms and rules that become entrenched amongst members of a network. Following professional standards and practices amongst a network can be a source of normative pressures. Mimetic pressure occurs when organizations imitate each other due to similar changes occurring in organizations that are alike or in the same industry, usually when these organizations are not certain about what to do. The actions of competitors are a particularly relevant source of mimetic pressure. In summary, the three elements - coercive, normative and mimetic, all have their distinctive features and ways in which they operate. However, Scott (2008) pointed out that in most empirically observed institutional forms, a combination of the elements are observed at work which can lead to the formation of a stable social system.

According to Weerakkody et al., (2009) the manner in which organizations respond to changes is often dependent on the socio-political, economic and technological influences exerted by the environment in which they operate. Thus the impacts of such external forces on organizational behavior have been studied by many researchers using the institutional theory. Orlikowski \& Barley, (2001) are of the view that institutional analysis has the potential to help researchers understand how institutions influence the design, use, and consequences of technologies, either within or across organizations.

Teo, Wei, \& Benbasat (2003) have studied the adoption of electronic data/information interchange (EDI) to which they found evidences of the influences of all three institutional pressures. In a similar study that applied methods proposed by Teo et al., (2003), Son \& Benbasat (2004) investigated the impetus for organizational participation in Business-to-Business electronic marketplaces to which they also found evidences of the significant influences of mimetic and normative pressures on the intention to adopt.

In this paper, the strength of the institutions theory is employed as an analytical lens to compare the various factors affecting the use of cloud hosted applications in the selected regions.

\section{FINDINGS AND DISCUSSION}

As this paper builds upon the work by Dahiru et.al (2014b) which used selected theoretical underpinnings of the institutional theory to analyze cloud computing adoption in sub-Saharan Africa, the findings are first presented and then subsequently compared with that of El-Gazzar (2014) which concentrated on Europe and Norway in particular. In the study by Dahiru et al. (2014), fifteen exciters (enablers) and inhibitors to cloud computing adoption were identified through the analysis of data collected from eighteen enterprises in Nigeria. These include security, privacy and trust, business growth, top management support, flexibility, scalability and competitive advantage, and government policy and regulations. Others are fear of data loss and cheaper and functional access to computing resources. Other cloud adoption issues identified in the study include internet connectivity issues, job loss and sabotage, lack of awareness, SLAs, implementation, training and change management, loss of total control over data and lack of experience or expertise. There is also the issue of cost which has been identified as both an exciter and inhibitor by various participants in the study.

As earlier stated El-Gazzar (2014) has also outlined some challenges being faced by cloud computing adopters in Norway specifically and in other European countries. These challenges include security, privacy and trust, increased complexity and cost, SLAs, hazy legal issues and governance policies, loss of control over data, lack of cloud ready compliance frameworks and lack of common jurisdiction especially amongst European Union (EU) member countries.

As can be seen from the findings drawn from the two studies, (Dahiru, et al. 2014b) and (El-Gazzar 2014), there are issues related to cloud computing adoption from both places (regions) that are similar and dissimilar. However, to establish a bases for comparison, only the five issues that are exhibited and addressed in both studies will be further examined and discussed in section V. 


\section{A Comparison of Cloud Adoption Issues in Europe and Sub-Saharan Africa}

Five key issues sparked the most interest in determining the similarities and differences in the challenges to cloud computing adoption in Europe and sub-Saharan Africa. These are:

\section{A. Security, Privacy and Trust}

Security, privacy and trust issues have been major concerns even before the introduction of cloud computing and plays a major role in the decision to adopt cloud hosted applications and services. In sub-Saharan Africa however, as can be inferred from the Dahiru et.al (2014) study; security, privacy \& trust are not seen as major threats. Concerning security and trust for instance, one participant from the study noted that "what prompted the [use of] cloud environment is looking at the kind of business that we do, for you to be able to have a secured environment for customers to be able to (like) trust their payments, [from] the three options we had, we saw that [chose] cloud as one of the best that can provide security for our information and data. So, as at the time we set up, their option was better than us having it in-house". According to another participant from the same study, while cloud computing may not be completely secured, it is still a better option. "I can't say it is 100\% secure... but it's for easy accessibility, it give(s) me what I need" the participant said. It can thus be seen that corporate and personal data have been put on the cloud by organizations in subSaharan Africa without recourse to its sensitivity.

The above submissions on security and privacy issues in sub-Saharan Africa are clearly contrary to findings from Europe, where El-Gazzar (2014) found out that the EU region has shown serious concerns regarding security, privacy and trust and several steps are being taken to address issues like risks to customers that can result due to this challenge. Evidences of coercive pressure can be traced or linked to some of the steps undertaken by governments in Europe to ensure that foreign cloud service providers abide by security and privacy directives related to cloud computing. This can however negatively influence the decision to adopt cloud computing.
In summary, whilst security, privacy and trust can pose an immediate challenge to cloud computing adoption in Europe, this is not entirely so for some organizations in sub-Saharan Africa as the issue itself has been identified more as enabling adoption rather than inhibiting it in a place where data is more likely to be tampered with locally.

\section{B. Increased Complexity and Cost}

Cost related issues play a major role and can influence the decision to adopt cloud computing. All except one of the participants in the Dahiru et al.'s (2014) study agree with the assertion that adopting cloud computing can benefit enterprises by reducing the cost of IT infrastructure development and/or maintenance. According to another participant from the same study, the issue of cost savings in the cloud is being exaggerated and that "if you look at the total cost of ownership, the differences might not still be much especially in an African situation". But another participant is of the view that the overhead cost of in-house IT maintenance pays for the cloud and when you look at the cost benefit it is worth it. One other participant from the Dahiru et al.'s (2014) study who is in the cloud service provisioning category also pointed out that "a lot of enterprises in sub-Saharan Africa are trying to change their CAPEX model to OPEX hence their desire to adopt the cloud". Furthermore, "the pricing model of the cloud and the availability of different service providers is what make it cost effective. At the same time, the cost of maintaining computing resources that relies heavily on electricity which is highly unreliable in many places in Africa is partially mitigated. This is as expressed by this interviewee: "it is cheaper to use the cloud especially here where there is a lot of power failure and since we are a solutions company we need to buy the enterprise license for our software[s] all the time".

While El-Gazzar (2014) has also confirmed cost as one of the top motives for using cloud computing in Norway, other cost related issues in Europe like the requirements for enormous audits and risks assessment to be conducted before the adoption of cloud computing may incur additional cost and pose as a hindrance. Consequently, it 
has become normal (normative pressure) or an industry standard to contract cloud consultancy firms in Europe to offer consultancy services when transitioning to the cloud. There is however no such need in most of the cases of cloud adoption in sub-Saharan Africa as cloud transitioning arrangements are mainly between service providers and their clients alone.

\section{Government Policy \& Regulations}

The study by Dahiru et al. (2014b) did not find evidence to support the existence of any form of government policy on data location or protection in Nigeria where data was collected. There is also no regulation limiting the kinds of cloud services to be used. One of the participants from the Dahiru et al.'s (2014b) study said that: "today there is no government policy on cloud solutions. I do know that, I have heard of a bill that's been sponsored, but to date there is nothing of such nature (so far)". There is however a monitoring professional body or a government agency responsible for ascertaining the delivery of reliable electronic services or other outsourcing processes. According to one other participant from the study however, "as the cloud infrastructure is growing and people are beginning to become more aware, definitely certain types of legislations have to be put in place so that you can have a kind of control on the entire IT cloud infrastructure".

Indeed, government regulation can have either a beneficial or a detrimental effect on innovation adoption (Baker 2012 ). The lack of interference from government at present, in relation to data location restrictions is perceived to have encouraged the growth of cloud hosted services adoption in Nigeria especially by medium-sized enterprises. On the other hand, government interference in Ethiopia and its tight grip on the telecom sector for instance has caused slow adoption (Freedom House 2014).

In Europe, as pointed out by El-Gazzar (2014), the hazy and difficult to understand legal issues and governance policies are posing a challenge to cloud adoption. Where data centers of cloud service providers are located outside Europe, the PATRIOT act has for instance impacted negatively on adoption decisions of cloud customers.

\section{Service Level Agreements (SLAs)}

SLAs for cloud computing clients in sub-Saharan Africa bother around service definition, service measurement, responsibilities and even rates. There are varying views regarding SLAs and the existence of relationship with cost. According to one of the participants from Dahiru et al.'s (2014b) study, "SLAs are tailored to almost what we want, harmonizing SLA with provider is not always an issue" One other participant from the same study who is in the cloud brokerage business asserted that if they are providing a direct service to a client, there has to be an agreed SLA but if a third party is involved, they normally have what they term as an "underpinning contract". Another participant from the same study affirmed that they extend the SLAs of their partners, i.e. the main provider of the cloud hosted service.

In Europe however, there is a bigger challenge according to El-Gazzar (2014) in managing an influencing cloud providers' SLAs. There is limited room for negotiations and even where cloud providers and clients agree, harmonizing the SLAs and legislative and/or regulative policies further becomes difficult despite drafting guidelines about relevant regulations on cloud services procurement by the government of Norway.

\section{E. Loss of Control over Data}

Loss of control has been identified as a factor that can inhibit the adoption of cloud computing. It has been linked with trust, poor internet connectivity and data loss in the Dahiru et al.'s (2014) study.

Similarly, El-Gazzar (2014) found out that for Norwegian organizations, there are serious concerns regarding the possibility of total loss of control over data due to the borderless nature of cloud computing and its mode of delivery, that sometimes makes it difficult to determine where data is processed and by who. This can in turn impact negatively on adoption.

Despite the concerns regarding loss of control in both places however, an important note is the fact 
that organizations are still willing to go for the cloud. In sub-Saharan Africa for instance organizations that identified lack of control as their main concern regarding the cloud still transitioned to the cloud and affirmed that using the cloud has given them an edge over other organizations operating in the same industry with them.

Whilst policies are used to mitigate risks that can occur due to loss of control over data in Europe, in sub-Saharan Africa, organizations turn to each other in establishing the right cloud vendor (provider) as the main factor that can be used to mitigate loss of control issues.

\section{CONCLUSION}

This research contributes to filling the literature gap in cloud computing adoption. With the aid of institutional analysis, the adoption of cloud computing in Europe and sub-Saharan Africa is examined and compared. Findings from this research show that, whilst challenges like security, privacy and trust, cost, SLAs and government policies and regulations draw a lot of concern when considering adoption, they impact and influence adoption decisions and transitioning to the cloud in different ways in the two regions.

In sub-Saharan Africa, key adoption issues that were used as bases for comparison, viz. security, privacy and trust, cost, SLAs, government policies and regulations and loss of control do not have a negative influence on adoption. Security, privacy and trust, and cost issues for instance are not seen as inhibiting cloud computing adoption; the reason being: a) the expectation of better and reliable security provision and data storage in the cloud compared to locally provided security and data hosting services; b) cheaper/functional access to computing resources that enhances operations and service delivery. Likewise, issues concerning SLAs and government regulations do not seem to have reached the maturity to influence adoption decisions. Whilst SLAs are simply agreed upon and harmonized by users and their service providers, government policy and regulations concerning data location and restrictions are simply non-existent.

On the other hand, same cannot be concluded for key adoption issues used as bases for comparison in Europe. Security, privacy and trust, cost, SLAs, government policies and regulations and loss of control over data can all inhibit or pose as hindrances to cloud computing adoption. Some of the steps undertaken by governments in Europe to ensure that foreign cloud service providers abide by security and privacy directives relating to cloud computing adoption can for instance negatively influence the decision to adopt cloud computing. Furthermore, whilst cost has a positive influence in both Europe and subSaharan Africa, consultancy services for risk assessment in Europe can introduce additional costs that can negatively influence adoption decisions. The hazy and difficult to understand governance policies, and managing and influencing cloud providers' SLAs are also impacting negatively on cloud computing adoption as there is limited room for negotiations.

Finally, whilst the effect of two of the institutional pressures; normative and coercive are profoundly noticed in Europe to potentially strengthen cloud computing usage, they can have a negative influence on adoption. On the other hand, the absence of these institutional pressures in subSaharan Africa does not seem to have affected adoption at present. Nevertheless, as the use of cloud computing grows in sub-Saharan Africa, and some of the risks and challenges become more apparent, users (providers inclusive) in the region will have many lessons to learn from their European counterparts. The approach undertaken in Europe to influence some of the key adoption issues in order to strengthen cloud computing usage may be inevitable.

As future work, more locations can be considered in both regions to have a wider and better perspective of the key issues that influence cloud adoption. Primary data can also be collected from both regions to add rigor to the research.

\section{ACKNOWLEDGMENTS}

Special thanks to the Petroleum Technology Development Fund (PTDF) Nigeria, for sponsoring the research.

\section{REFERENCES}

Akande, A.O. and Van Belle, J., (2014). A proposed framework to assess and increase 
the cloud computing readiness of financial institutions in South Africa. Confluence The Next Generation Information Technology Summit (Confluence), 2014 5th International Conference-. IEEE. pp. 46-52

Alex, C., (2011). Emerging Issues: Cloud Computing. [Online] Available from: https://www.apc.org/en/system/files/1.Cloud Computing.pd

Alshamaila, Y., Papagiannidis, S. and LI, F., (2013). Cloud computing adoption by SMEs in the north east of England: A multiperspective framework. Journal of Enterprise Information Management, 26(3): 250-275

Baker, J., (2012). The technology-organizationenvironment framework. Information Systems Theory. Springer. pp. 231-245

Carcary, M., Doherty, E., Conway, G., \& McLaughlin, S. (2014). Cloud computing adoption readiness and benefit realization in Irish SMEs-An exploratory study. Information Systems Management

Clemens, E.S. and Cook, J.M., (1999). Politics and institutionalism: Explaining durability and change. Annual review of sociology, 25(1): 441-466

Dahiru, A.A., Bass, J. and Allison, I., (2014a). Cloud Computing: Adoption Issues for SubSaharan Africa SMEs. The Electronic Journal of Information Systems in Developing Countries, 62(1): 1-17

Dahiru, A.A., Bass, J.M. and Allison, I.K., (2014b). Cloud Computing Adoption in sub-Saharan Africa: An Analysis using Institutions and Capabilities. International Conference on Information Society (i-Society 2014). Infonomics Society. pp. 100-105

Datta, P., Byrd, T. A., Okoli, C., \& Mbarika, V. W. (2005). The neglected continent of IS research: A research agenda for subSaharan Africa. Journal of the Association for Information Systems, 6(5): 6.

Dimaggio, P.J. and Powell, W.W., (1983). The iron cage revisited: Institutional isomorphism and collective rationality in organizational fields. American Sociological Review, 48(2): 147-160

EL-Gazzar, R.F., (2014). An Overview of Cloud Computing Adoption Challenges in the Norwegian Context. Utility and Cloud
Computing (UCC), 2014 IEEE/ACM 7th International Conference on. IEEE. pp. 412418

Freedom House, (2014). Freedom on the net obstacle to access, Ethiopia. [online] Available from: https://freedomhouse.org/report/freedomnet/2013/ethiopia\#.VKqs5YusV8F

Greengard, S., (2010). Cloud computing and developing nations. Commun.ACM, 53(5), pp. $18-20$

Hulme, G.V., (2011). NIST formalizes cloud computing definition, issues security and privacy guidance. 2011 http://www.csoonline.com/article/66162 0/nist-formalizes-cloud-computing definitionissues-security-and privacy-guidance

Jennings, P.D. and Greenwood, R., (2003). 6bConstructing the Iron Cage: Institutional Theory and Enactment'. Debating organization: point-counterpoint in organization studies, 195

Kshetri, N., (2011). Cloud Computing in the Global South: drivers, effects and policy measures. Third World Quarterly, 32(6): 997-1014

Lumsden, J.R.I. and Anabel, G., (2013). Understanding the Determinants of Cloud Computing Adoption within the UK. Proceedings of the European, Mediterranean \& Middle Eastern Conference on Information Systems (EMCIS).

Miles, J.A., (2012). Management and Organization Theory: A Jossey-Bass Reader. John Wiley \& Sons.

National Bureau of Statistics, (2014). Nigeria economy largest in Africa. [online] Nigeria: Available from: http://nigerianstat.gov.ng/ [Accessed June/03 2014]

Orlikowski, W.J. and Barley, S.R., (2001). Technology and institutions: what can research on information technology and research on organizations learn from each other? MIS quarterly, 25(2): 145-165

Saya, S., Pee, L.G. and Kankanhalli, A., (2010). The Impact of Institutional Influences on Perceived Technological Characteristics and Real Options in Cloud Computing Adoption in Proceedings of the 31st International 
Conference on Information Systems (ICIS), St. Louis, December 12-15, 2010.

Scott, R. W. (2008). Institutions and organizations: Ideas and interests. Sage Publications.

Son, J. and Benbasat, I., (2004). Organizational Adoption and Use of B2B Electronic Marketplaces: Efficiency-and LegitimacyOriented Perspectives. University of British Columbia, Vancouver,

Teo, H., Wei, K.K. and Benbasat, I., (2003). Predicting intention to adopt interorganizational linkages: An institutional perspective. MIS Quarterly, 27(1): 9-49

Voorsluys, W., Broberg, J. and Buyya, R., (2011). Introduction to Cloud Computing. Cloud
Computing. John Wiley \& Sons, Inc. pp. 141

Walsham, G. and Sahay, S., (2006). Research on information systems in developing countries: Current landscape and future prospects. Information Technology for Development, 12(1): 7-24

Weerakkody, V., Dwivedi, Y.K. and Irani, Z., (2009). The diffusion and use of institutional theory: a cross-disciplinary longitudinal literature survey. Journal of Information Technology, 24(4): 354-368

Werfs, M., Baxter, G., Allison, I. K., \& Sommerville, I. (2013). Migrating software products to the cloud. Journal of International Technology and Information Management, 22(3): 3. 